УДК 372.881.161.1

ББК 74.489

\section{Е.Н. Бекасова}

\section{ТРАДИЦИИ «ПОЧИТАНИЯ КНИЖНОГО॥ КАК ЦЕННОСТНЫЙ ОРИЕНТИР COBPEMEHНOГO ФИЛОЛОГИЧЕСКОГО ОБРАЗОВАНИЯ}

Тысячелетняя традиция «почитания книжного» является одним из важных компонентов образовательной системы и общественного просвещения, движимых в том числе интеллектуальной и духовной рефлексией просветителей Кирилла и Мефодия. Однако анализ современных интернет-ресурсов и мониторинг знаний школьников показывает необходимость усиления использования данного направления для восполнения лакун образовательного процесса, что обусловливает проведение ряда научно-просвещенческих мероприятий, приуроченных к Дню памяти славянских учителей и других дат, связанных с языком и книжностью.

Ключевые слова: филологическое образование, проектная деятельность, День славянской письменности и культуры, просвещение, деятельность Кирилла и Мефодия, глаголииа, кириллища.

DOI 10.18522/1995-0640-2020-3-185-196

Бекасова Елена Николаевна - докт. филол. наук, доцент, профессор кафедры русского языка и методики преподавания русского языка Оренбургского государственного педагогического университета Тел: +7-922-552-93-29

E-mail: bekasova@mail.ru

(C) Бекасова Е.Н., 2020.
Хрестоматийная дата первого тысячелетия государства Российского была отмечена грандиозным монументом, символически представляющим основные этапы формирования и развития истории государства, где начальным камнем его духовности стала композиция «Крещение Руси», открывающая страницу просвещения народа. Во главе зачинателей нового периода развития Руси находятся фигуры Учителей славянского народа Константина Философа и Мефодия. В год празднования тысячелетия ещё глубоко осознавалась неразрывная связь Российского государства с деятельностью просветителей славянства, которая с течением времени была предана забвению. Потеря исторической памяти и сейчас приносит свои горькие плоды, даже после установления в 1991 г. Дня славянской письменности и культуры, приуроченного к Дню памяти первоучителей славянских народов, святых равноапостольных братьев Кирилла и Мефодия, и сложившейся в последнее время традиция совместного празднования государственными и общественными организациями совместно с Русской Православной церковью более чем тысячелетней даты. Однако не везде и не всегда отдаётся должное великому событию просвещения славянства. При этом следует подчеркнуть, что один день не может ликвидировать невежество граждан в данном вопросе и устранить соответствующую брешь в школьном и, к сожалению, вузовском образовании. Например, ежегодное анкетирование первокурсников филологического факультета 
Оренбургского государственного педагогического университета показывает, что большинство из них в школе не слышали о Кирилле и Мефодии; они затрудняются назвать наиболее значимые даты их подвижнической деятельности; не знают, в чём заслуга братьев перед славянами и другими народами и практически не соотносят древнейшие славянские алфавитные системы с именами Учителей славянского народа. Эти данные подтверждаются результатами олимпиад, где оренбургские знатоки русского языка не могут выстроить рассказ о деятельности Кирилла и Мефодия; выдвигают предположения, что современный русский алфавит является латиницей и даже «мефодицей», а русский язык относится к тюркской семье языков; не понимают, что такое древнейший литературно-письменный язык славян и какова его роль в истории русского литературного языка. К сожалению, такое положение закономерно вытекает из особенностей современной подготовки учителей-словесников, поскольку практически все учебные планы отражают значительное количество часов на изучение, например, важнейшей источниковедческой дисциплины славянских языков - старославянского языка - планируется такое количество часов, которое не позволяет в полной мере раскрыть деятельность Кирилла и Мефодия и её выдающуюся роль в становлении и развитии русского литературного языка, что не содействует восполнению вековой потери российской исторической памяти [Бекасова, 2017, с. 48 - 49; Изотов, 2007, с. 11 - 14]. Иными словами, мы имеем дело не только с упущенным воспитательным и образовательным ресурсом, сколько не противодействуем стремительному разрушению нашей ментальности вследствие «неорганического вторжения чужеродных ментальных категорий» [Колесов, 1999, с. 137] на фоне легкомысленного стремления к креативности и предельной индивидуальности, оборачивающимися в итоге невежеством и забвением традиционных человеческих, славянских и российских ценностей.

Такое положение обусловливает необходимость подготовки учителей-словесников научно достоверными знаниями о деятельности Кирилла, Мефодия и их учеников и оснащения студентов определённым багажом методов и форм осуществления образовательной и воспитательной работы по данному направлению. Отсюда и цель данной статьи - обобщение и систематизация опыта проведения мероприятий различного формата, посвящённых деятельности славянских первоучителей и сохранению традиций «почитания книжного».

Следует признать, что существует огромная литература о деятельности солунских братьев, однако её популяризация, как правило, приводит к распространению многочисленных мифов, которые в условиях полной свободы, в том числе и от просвещенческих традиций, активно пополняются ненаучными измышлениями различного толка. Как ни парадоксально, причиной этому служит особая притягательность и значимость деятельности Учителей славянского народа, а также наличие весьма объёмного научного материала, поскольку кирилло-мефодиевская проблематика, как отмечают С.Б. Бернштейн и Г. А. Хабургаев со 
ссылкой на В.И. Ламанского, представляла и представляет «главную привлекательную силу в истории славянской филологии» [Бернштейн, 1984, с. 4; Хабургаев, 1994, с. 9]. Для ознакомления с такой научной литературой требуется специальная подготовка, однако среди них можно выделить ряд научных изданий, представляющих интерес и для широкой публики, так как позволяют извлечь достоверную информацию и ознакомиться с важнейшими текстами, освещающими жизнь и деятельность Кирилла и Мефодия, их учеников и последователей, а также становление традиций многовекового почитания книжности [Бернштейн, 1984; Хабургаев, 1994; Сказание, 1981; Флоря, 2000; Тахиоас, 2005]. Особо надо отметить, что в этих книгах представлен весь спектр наиболее проблемных «зон» славяноведения, что позволяет вникнуть в развернувшиеся дискуссии и не уходить в сторону невежественных фантазий [Верещагин, 2006, с. 651 - 664].

Однако анализ ряда сайтов (включая образовательные, чаще всего ориентированные на школьников, учителей и воспитателей детских учреждений), где в том или ином объёме подаётся информация о деятельности Кирилла и Мефодия, показывает, что в них нередко содержится целый ряд таких сведений о просветителях славянского народа, которые можно назвать своеобразным «учебным» мифотворчеством, идущим вразрез со всеми научными знаниями. С одной стороны, разрушается историко-культурный фон эпохи, в результате чего Кирилл Философ представляется то преподавателем философии, которую он знал лучше университетских профессоров, то просто библиотекарем. Более того, на уроке для подготовительной группы детского сада в былинном стиле повествуется о «святой Руси, о далёких временах, вам неведомых», когда жили 7 братьев и «явились два просветителя, мудрые братья»: старший управлял княжеством, младший «мечтал писать книги и придумал славянские буквы» - «и долгое время на Руси была одна книга Евангелие, по которой учились дети», «на Руси стали строить храмы, а Кирилл ходил и освещал их». Адаптация к детскому восприятию сведений, которыми не вполне владеет автор урока, оборачивается вульгаризацией исторических реалий и необходимостью выправления историко-географической «кривизны». С другой стороны, сложнейшие проблемы изучения многовековой Кирилло-Мефодиевской традиции, их философское, историческое, культурное и филологическое преломление в современной науке трудно изложить в популярной форме, особенно с учётом более чем тысячелетнего разрыва. Это в большей степени касается феномена древнейших славянских азбук. По версии интернет-«информации» для школьников, Кирилл создал (придумал/сочинил) кириллицу и называл её в честь себя; братья придумали глаголицу для западных славян, а кириллицу - специально для Киевской Руси; глаголица на Руси использовалась для «передачи церковнославянских текстов», в бытовой письменности использовалась кириллица и т.п. И это только часть доступных всем интернет-ресурсов, где находится, как совершенно точно в своё время определил А.А. Зализняк, «гора абсурдов, дилетантской 
чепухи и фантасмагорических вымыслов», игнорирующих «профессиональную науку и здравый смысл» [Зализняк, 2009, с. 131]. Оставляя в стороне проблемы популяризации научных знаний, диагностирования объёма, критериев отбора и подачи информации, доступной для детей разного возраста, считаем, что в данном случае срабатывают не только объективные факторы, обусловленные феноменом просвещения славян, но и субъективные, которые отметил ещё М.В. Ломоносов. Анализируя околонаучный «поток, несущий в своих водах одинаково и истину и ложь, и бесспорное и небесспорное», великий учёный особо отмечает злостность тех сочинений, в которых «скрываются небрежность, невежество, поспешность, дух пристрастия и недобросовестности» [Ломоносов, 1980, с. 124], и некоторых авторов, не обладающих «тенью стыда и остатками совести», но задающихся «целью ввести в заблуждение весь мир» [Там же, с. 122-123].

Материал данной статьи был получен в результате анализа научной литературы по проблеме; описания целого ряда мероприятий, посвящённых теме просвещения; систематизации и обобщения полученных результатов.

Безусловно, деятельность Первоучителей славянства - это важный этап в жизни российского народа, ментальность которого складывалась и прирастала кирилло-мефодиевскими традициями почитания книжного и достижениями церковнославянского языка, который отпечатался в русском языке, и это запечатление не даёт оборвать незримые нити просветительского притяжения к свету духовности [Бекасова, 2013, c. $150-208]$.

Не следует забывать, что важнейшим посылом Константина Философа к переводу Библии было чувство равенства всех народов перед Богом, что особенно сильно прозвучало в его утверждении прав славянских книг встать рядом с книжностью других народов, о чём со всей определённостью написано в «Житии Константина»: «Не идёт ли дождь от бога равно на всех, не сияет ли для всех солнце, не равно ли все мы вдыхаем воздух? Как же вы не стыдитесь лишь три языка признавать, а прочим всем народам и племенам велите быть слепыми и глухими? Скажите мне, зачем делаете Бога немощным, как если бы не мог дать народам своего письма, или завистливым, как если бы не хотел дать? Горе вам, книжники, что взяли себе ключ к познанию. Сами не входите и хотящим войти возбраняете» [Сказание, 1981, с. 89]. Это позволило через переводы славянам «причтеся к великим языщам» и отлучиться им «от жития скотска и похоти». Следует особо отметить, что просветители славянства не были обычными миссионерами, но для того времени христианская ориентация была основной частью просвещения народа «слышити ныне от своего ума, слышите словенск народ, слышати слово, от Бога прииде... бес книг язык в гласе смыслене не глаголюште... Нази бо въси без книг языии» [Топоров, 1995, с. 89]. При этом переводы важнейших, отработанных веками конфессиональных текстов с греческого литературного языка на родной для славян язык позволяли восприни- 
мать не столько новую религию, сколько то мировосприятие, которое начинает формировать нового человека, с его особой ментальностью, вбирающей в себя достижения великих цивилизаций. Накопленная научная литература о деятельности Учителей и Учеников со всей определённостью показывает, что они понимали значимость своей просветительской деятельности, которую выполнили в наиболее продуктивной для славянского народа форме, что доказано тысячелетней традицией «почитания книжного».

К сожалению, у наших граждан нередко приходится констатировать отсутствие понимания значимости славянской письменности, какое мы находим у Черноризца Храбра в его сочинении «О письменах», когда ещё были живы свидетели духовного подвига Кирилла и Мефодия и их учеников: «Ведь если спросишь книжников греческих, говоря: кто создал вам письмена или книги перевёл и в какое время, то мало кто среди них это знает. Если же спросишь славянских книжников, то все знают и, отвечая, говорят: святой Константин Философ, названный Кириллом, он письмена создал, и книги перевёл, и Мефодий, брат его в лето 863» [Сказание, 1981, с. 104]. Отсутствие знаний «откуду есть пошла» наша письменность, наше славянское мировоззрение и традиции книжного почитания во многом редуцирует не только тысячелетнюю память о самых важных проявлениях человеческого духа, но и историю российского просвещения, языка, литературы и культуры. И ещё шире не раскрывает особенностей русской ментальности - «миросозерцания в категориях и формах родного языка, соединяющее в процессе познания интеллектуальные, духовные и волевые качества национального характера в типичных его проявлениях» [Колесов, 1999, с. 81], поскольку русский литературный язык развивался под влиянием церковнославянского, который «усыновил его, избавя таким образом от медленных усовершенствований времени» [Пушкин, 1994, с. 136]. Более того, без прославления Учителей славянского народа Кирилла и Мефодия, без кирилло-мефодиевских традиций почитания книжного постепенно ускользает то главное, что выстраивало величественное здание русского мира в сохранении достижений эллино-средиземноморской культуры, письменности и христианства в соединении с всепоглощающей жаждой знаний «новых людей» [Бекасова, 2012].

Утрата исторической памяти, агрессивность «маргинализирующей истории кирилло-мефодиевской традиции» [Полывянный, 2018, с. 65] обусловливает необходимость просвещенческих действий, связанных с одним из важнейших событий в истории славянства и становления русской государственности, письменности и культуры. Вследствие этого, начиная с 2003 года, на базе Оренбургского государственного педагогического университета с участием Правительства Оренбургской области (с перерывом с 2014 по 2018 гг.), силами кафедры языкознания и МПРЯ (с 2017 г. - кафедра русского языка и МПРЯ), научно-исследовательской лаборатории «Междисциплинарные лингвистические исследования» проводятся торжественные научно-просвещенческие 
собрания, посвящённые Дню славянской письменности и культуры, которые с 2006 г. по 2015 г. являлись итогом проведения региональных конференций и были отражены в ряде сборников материалов [Славяне..., 2011; Славяне..., 2013; Славяне... 2014], других публикациях и на сайте Оренбургского государственного педагогического университета (https://ospu.ru/ru/).

Как правило, мероприятия посвящаются одному из аспектов богатейшей истории возникновения и распространения славянской письменности, представленному в различных формах: торжественных приветствиях, научных докладах преподавателей и студентов; дискуссиях, инсценировках, всевозможных конкурсах и пр. Например, сценарий 2010 г. «Наставники и учителя славянского народа (сценарий для литературно-музыкальной композиции, посвящённой просветителям славянского народа святым равноапостольным Кириллу и Мефодию)», опубликованный в сборнике материалов конференции [Славяне..., 2011, c. 82-87] и отчасти повторённый в 2017 г. [Сайт ОГПУ], был посвящён историко-культурным предпосылкам появления славянской письменности и деятельности Кирилла и Мефодия. Студенты филологического факультета представили основные фрагменты Жития Константина и Жития Мефодия, Сказания Черноризца Храбра, прочитали страницы Повести временных лет и показали значимость деятельности солунских братьев в оценках общественных деятелей, историков и филологов. Это в полной мере позволило прочувствовать тот дух традиций, которым веками пропитывался «сакральный ранг познания просветителей славян Кирилла и Мефодия» [Рыбаков, 2016, с. 72].

В 2013 юбилейном году празднование было посвящено древнейшей славянской азбуке - глаголице и её судьбе в славянском мире. В связи с этим были рассмотрены основные положения дискуссии о первенстве одной из двух древнейших славянских азбук, показаны древнейшие глаголические памятники старославянской письменности, выявлены особенности глаголицы и кириллицы, их предыстория и бытование в письменности [Славяне, 2014, с. 3-11]. К древнейшим алфавитным системам обратились и в 2017 г., когда подробно рассматривались история возникновения и судьба кириллицы в славянском и неславянском мире, научные точки зрения о генезисе алфавитных систем [Бекасова, 2017]. Так как заседание было посвящено памяти академика А.А. Зализняка, то особыми страницами программы стали объекты научных интересов известного учёного - древнейшие абециарии по показаниям памятников письменности, берестяным грамотам и знаменитому, найденному в 2000 г. Новгородскому кодексу, которые являются доказательствами стремительного распространения письменности в Древней Руси после её крещения. Интерес к этой теме был настолько сильным, что на факультете появился ежегодный, пользующийся особым успехом конкурс «Поклон от Онфима», в котором студенты представляют свои первые шаги в письменности. За эти годы собралась большая коллекция первых детских букв, слов и рисунков, которые позволяют их сопоставить 
с упражнениями новгородского мальчика XIII в. Онфима. Факультетское собрание детского восприятия одного из важнейших открытий человечества привело к мысли составления оригинальных букварей, азбук, азбуковников, которые бы отражали главные ценности нашего общества и содержали сведения о зарождении славянской письменности. Как правило, такие первые книжки становились семейным делом, в результате чего проект получил название «Семейная азбука (для детей и их родителей)».

Следует отметить, что 24 мая, как правило, становится итоговым торжественным собранием, поскольку сложилась целая система различного типа научно-просветительских мероприятий, которые в той или иной степени обращаются к теме славянского просвещения, деятельности Учителей славян и традиций «почитания книжного». В частности, постепенно сложились постоянные рубрики мероприятий, проводимых совместно с Оренбургской областной универсальной научной библиотекой им. Н. К. Крупской: лекторий «Филология в лицах», региональный конкурс «Сокровище родного слова», фестиваль научных проектов «Филологические прогулки с В.И. Далем», празднование Дня родного языка и Дня первой русской печатной книги. Отчёты о прошедших мероприятиях систематически выставляются на сайте Оренбургского государственного педагогического университета.

Показателем того, что все направления связаны главной темой «почитания книжного» является, например, круглый стол «Семена духовные» (2014 г.), посвящённый «Апостолу» первопечатника Ивана Фёдорова. Дата 450-летия первой русской печатной книги стала поводом вспомнить не только значимость печатного дела для развития русской письменности и культуры, но и великое дело справщика рукописных текстов. Эта дата позволила объединить общеславянские, восточнославянские и русские звенья единой цепи просвещения человечества главным символом «исходищ, мудрости» - семенами духовными. В этом случае технический прогресс не смог прервать духовную нить многих поколений книжников, для которых образы Пахаря и сеятеля всегда олицетворялась с тяжёлым бескорыстным трудом сеятелей духовных семян, когда одни посеяли семена книжные, другие пожинают «ученъе приемлюще книжное», а третьи с немыслимой для рукописания скоростью раздают «духовную пищу» всей вселенной: так «работа многих поколений поддерживала энергию книжных текстов, создавая постоянно пополняемую сокровищницу идей и слов, из которой произрастала культура и книжность» [Славяне..., 2014, с. 10].

Торжественные собрания, посвящённые юбилеям И.И. Срезневского, А.А. Шахматова, Ф.И. Буслаева, В.В. Виноградова, Н.С. Трубецкого, И.А. Бодуэна де Куртенэ в силу их творческого наследия также в той или иной степени затрагивали проблему влияния древнейшего литературно-письменного языка славян на становление и развитие русского литературного языка. Особо следует отметить посвященное Н.С. Трубецкому «сопряжённое» занятие для бакалавров, получающих образо- 
вание с двумя профилями подготовки (русский язык и литература, русский язык и история, русский язык и начальное образование). Одним из ключевых моментов открытого занятия, где студенты разных групп представили разные грани жизни, деятельности и творчества одного из выдающихся русских мыслителей, стало рассмотрение значимости «общеславянского элемента» в системе русского литературного языка, который был определён Н.С. Трубецким как потенциально дарованное всем славянским языкам «драгоценнейшее богатство», но сопряжение с ним сделало только русский литературный язык «совершеннейшим орудием как теоретической мысли, так и художественного творчества» [Трубецкой, 1990, с. 124]. Студентам настолько понравилось такое инновационное занятие, что они высказали желание подобным образом отметить юбилей В.В. Виноградова, труды которого внесли значительный вклад в определение феномена старославянского языка и его взаимодействия с русским языком.

Следует отметить, что традиционно мероприятия готовятся совместными усилиями преподавателей и студентов. Как правило, преподаватель в своём научном докладе затрагивает основные моменты рассматриваемой темы, которые в дальнейшем в той или иной степени представляют студенты в собственных научных докладах, презентациях и сценариях. Такие творческие проекты готовятся в течение всего учебного года в рамках историко-лингвистических дисциплин («Старославянский язык», «Классические языки», «История русского языка», «Славянские языки», «Введение в славянскую филологию» и др.) и становятся итогом научно-исследовательской деятельности бакалавров.

Это важный аспект подготовки будущих учителей русского языка, поскольку в учебных планах неуклонно сокращается количество часов на изучение истории языка - фундамента подготовки профессионала, поскольку, по справедливому утверждению В.В. Колесова, «все гуманитарные науки в своей основе историчны», а «историзм их и есть та искомая теория, которая каждую научную дисциплину делает наукой, актуальной до сегодняшнего дня» [Колесов, 1999, с. 338].

Итогом всех мероприятий становится традиционный региональный конкурс «Славянская письменность как историко-культурное достояние», который затрагивает тему-посвящение Дня славянской письменности и культуры (например, вопросы, связанные с древнейшими азбуками, памятниками письменности, реформами кириллицы, использованием кириллицы для алфавитных систем других языков, осмыслением азбуки в устном народном творчестве, пониманием алфавита как духовно-культурного феномена народа и под.). В конкурсе участвуют не только студенты вузов и семинарии, но и учащиеся школ, лицеев гимназий, кадетских училищ Оренбуржья.

Возникновение славянской азбуки и переводов на славянский язык конфессиональных текстов как достижений средневековья является главной датой памяти всех славян об «ослепительной культурной вспышке зарождения оригинального славянского письма» [Трубачев, 
2005, с. 24], об Учителях и их учениках, которыми утверждалась и утверждается главная суть духовной жизни человечества. Всё это требует особого, пристального внимания к более чем тысячелетней традиции «почитания книжного», что важно для обучения и воспитания поколения будущих учителей-словесников, которые не только владеют соответствующим материалом, но и умеют формировать духовное образовательное пространство и реализовать его культурно-нравственный и духовно-просветительский потенциал.

При этом системная работа в течение учебного года реализует научный и воспитательный потенциал главной темы Дня славянской письменности и культуры, соединяя её с уважением к культуре, письменности, истории и личностям, которые выстраивают их в истинно цивилизационном, человеческом ключе.

\section{Литература}

Бекасова Е.Н. (2017) Азбука как ключ к познанию мира // Филологический класс. Науч.-метод. журнал. № 4 (50). Екатеринбург: Изд-во Уральского гос. пед. ун-та. С. $44-49$.

Бекасова Е.Н. (2012) Древнерусский текст как феномен греко-славянского культурного мира // Вестн. ОГПУ. Вып. 2 (2). С. 42 - 48.

Бекасова Е.Н., Москальчук Г.Г., Прокофъева В.Ю. (2013) Векторы интерпретации текста: структуры, смыслы, генезис: монография. М.: Изд-во Спутник+. $217 \mathrm{c}$.

Бернштейн С.Б. (1984) Константин-Философ и Мефодий. М.: Изд-во Моск. ун-та. $167 \mathrm{c}$.

Верещагин Е.M. (2005-2006) Рецензия на русский перевод книги: Тахиаос Антоний-Эмилий Н. Святые братья Кирилл и Мефодий, просветители славян // Богословский вестн. № 5-6. С. 650-669.

Зализняк А.А. (2009) Из заметок о любительской лингвистике. М.: Русскій Міръ: Московские учеб. 240 с. (Серия «Литературная премия Александра Солженицына»). тис. $232 \mathrm{c}$.

Изотов А.И. (2007) Старославянский и церковные языки. М.: Филомай-

Колесов В.В. (1999) «Жизнь происходит от слова...». СПб.: «Златоуст». 369 с. (Язык и время. Вып. 2).

Ломоносов М.В. (1980) Избранная проза / сост., вступит. статья и коммент. В. А. Дмитриева. М.: Сов. Россия. 519 с.

Польвянный Д.И. (2018) Западный вектор Кирилло-Мефодевского славянства и Русь в Х в. // Русин. Т. 51, вып. 1. С. 65-78.

Пушкин А.С. (1994) Собр. соч.: в 5 т. Т. 5: Автобиографическая проза. Отрывки. Афоризмы. Критика. Публицистка. Исторические сочинения. СПб.: Библиополис. $802 \mathrm{c}$.

Рыбаков С.В. (2016) Отстаивание идеи славянского просвещения в Житиях Кирилла и Мефодия // Учён. записки Орловского гос. ун-та. № 3 (72). C. $69-73$.

Сказание о начале славянской письменности (1981). М.: Наука. 199 с. (Памятники средневековой истории народов Центральной иВосточной Европы). 
Славяне в этнокультурном пространстве Южно-Уральского региона (2011): материалы межрегиональных науч.-практ. конф. Оренбург: ГУП Оренбургской области «Бузулукская типография». 242 с.

Славяне в этнокультурном пространстве Южно-Уральского региона (2013): материалы VIII Межрегиональной науч.-практ. конф., посвященной Дню славянской письменности и культуры в Оренбуржье. Оренбург: ООО ИПК «Университет». $374 \mathrm{c}$.

Славяне в этнокультурном пространстве Южно-Уральского региона (2014): материалы Х Междунар. науч.-практ. конф., посвященной Дню славянской письменности и культуры. Оренбург: ООО ИПК «Университет». 366 с.

Тахиаос Антоний-Эмилий Н. (2005) Святые братья Кирилл и Мефодй, просветители славян. Сергиев Посад. 391 с.

Топоров В.Н. (1995) Святость и святые в русской духовной культуре. Т. 1: Первый век христианства на Руси. М.: «Гнозис». Школа «Языки русской культуры». $876 \mathrm{c}$.

Трубачёв О.Н. (2005) В поисках единства: взгляд философа на проблему истоков Руси: 3-е изд., доп. М.: Наука. 286 с.

Трубецкой Н.С. (1990) Общеславянский элемент в русской культуре // Вопросы языкознания. № 3. С. 114-134.

Флоря Б.Н., Турилов А.А., Иванов С.А. (2000) Судьбы кирилло-мефодиевской традиции после Кирилла и Мефодия. СПб.: Алетейя. 314 с.

Хабургаев Г.А. (1994) Первые столетия славянской письменности и культуры: Истоки древнерусской книжности. М.: Изд-во Моск. ун-та. 181 с.

Сайт Оренбургского государственного педагогического университета [Электронный ресурс]. URL: https://ospu.ru/ru/ (дата обращения 10.03.2020).

\section{References}

Bekasova E.N. (2017) Azbuka as the key to knowledge of the world. Philological class. Scientific and methodical magazine. № 4 (50). Yekaterinburg: Publishing House: Ural State Pedagogical University. P. 44-49. (In Russian).

Bekasova E.N. (2012) Ancient Russian text as a phenomenon of the GrecoSlavic cultural world. Journal of OGPU, Issue 2(2), pp. 42-48. (In Russian).

Bekasova E.N., Moskalchuk G.G., Prokofieva V.Y. (2013) Vectors of text interpretation: Structures, Meanings, genesis: Monography. Moscow, Satellite+ 217 p. (In Russian).

Bernshtein S.B. (1984) Constantine-Philosopher and Mefodius. Moscow City. 167 p. (In Russian).

Floria B. N., Turilov A. A., Ivanov S.A. (2000) Fates of the Kirillo-Mephodian tradition after Cyril and Mephodius. SPb.: Алетейя. 314 p. (In Russian).

Haburgayev G.A. (1994) First centuries of Slavic writing and culture: Origins of ancient Russian bookishness. Moscow, MSU. 181 p. (In Russian).

Izotov A.I. (2007) Staroslavansky and church Slavonic languages. M.: Filomaytis,. 232 p. (In Russian).

Kolesov V.V. (1999) «Life comes from the word...». SPb., Zlatoust. 369 p. (Language and time. Issue 2).

Lomonosov M.V. (1980) Selected prose. Comp., will enter. article and comment. V.A. Dmitriyeva. Moscow, Sov. Rossiya. 519 p. (In Russian).

Polivyannyi D.I. (2018) Western vector of Kirillo-Mefodievsky Slavic and Rus in X century// Rusin, vol. 51, century 1, pp. 65-78. (In Russian). 
Pushkin A.S. Collection of works in five volumes. Vol. 5. Autobiographical prose. Fragments. Aphorisms. Criticism. Publitsistka. Historical compositions. SPb., Bibliopolis, 1994. 802 p. (In Russian).

Rybakov S.V. (2016) Advocacy of the idea of Slavonic education in the Lives of Kirill and Mefodi. Academic notes of Oryol State University, no. 3 (72), pp. 69-73 (In Russian).

The story of the beginning of Slavic writing (1981). Moscow, Nauka. 199 p. (Monuments of medieval history of the peoples of Central and Eastern Europe). (In Russian).

Slavs in the ethno-cultural space of the South Ural region (2011): materials of interregional science conferences. Orenburg: State University of Orenburg region «Buzuluk Printing House». 242 p. (In Russian).

Slavs in the ethnocultural space of the South Ural region (2013): materials of the VIII Interregional Scientific and Practical Conference dedicated to the Day of Slavic Writing and Culture in Orenburzhye. Orenburg: LLC IPK «University». 374 p. (In Russian).

Slavs in the ethno-cultural space of the South Ural region (2014): materials of the X International Scientific and Practical Conference dedicated to the Day of Slavic Writing and Culture. Orenburg: IPK «University». 366 p. (In Russian).

Tachiaos Antony-Emilius N. (2005) Holy brothers Cyril and Mefodi, educators of Slavs. Sergiyev Posad. 391 p. (In Russian).

Toporov V.N. (1995) Holiness and saints in Russian spiritual culture. Volume 1. The first century of Christianity in Russia. Moscow, «Gnosis». School «Languages of Russian Culture». 876 p. (In Russian).

Trubachev O.N. (2005) In search of unity: the view of the philosopher on the problem of origins of Rus. 3rd ed., additional. Moscow, Nauka. 286 p. (In Russian).

Trubetskoi N.S. (1990) The General Slavic Element in Russian Culture. Issues of Linguistics, no. 3, pp. 114-134 (In Russian).

URL: https://ospu.ru/ru/

Vereshchagin E.M. (2005-2006) Review of the Russian translation of the book: Tahiaos Antony-Emilia N. Holy Brothers Kirill and Mefodi, Educators of Slavs. Theological Gazette. № 5-6, pp. 650-669. (In Russian).

Zalizniak A.A. (2009) From notes about amateur linguistics. Moscow, Russki Mir: Moscow Studies. 240 p. (Series «Alexander Solzhenitsyn Literary Prize»). (In Russian).

Elena N. Bekasova (Orenburg, Russian Federation)

\section{Traditions of «Honouring the Bookish» as Value Orientation} in Modern Philological Education

A thousand-year tradition of «honouring the bookish» is one of the most important components of the educational system and social enlightenment, which is moved, among other things, by intellectual and spiritual reflection of the educators Cyril and Methodius. However, despite the fact that the national holiday of Slavic Alphabet and Culture has been present for twenty years, in modern conditions of weakening the historical memory and the significance of Christianity, there is a serious lack of information about the lives and activities of Konstantin the Philosopher, Methodius and their followers in the spiritual life of Slavdom and establishment of Russian mentality. That is why the great educational endeavor of the brothers of 
Thessaloniki, appropriately valued only in modern times, requires support from educational systems. Elaborating the details of historical and cultural preconditions to the appearance of the first Slavic ABC books, Bible translations and their existence in the Slavic world is extremely important to the future teachers of the Russian language and literature, and especially in the conditions of wide spread misinformation and decreasing amount of academic hours for studying the disciplines of historical and linguistic sciences, which, in one way or another, touch upon the problems of the origin of the ancient literary and scriptory language of the Slavic and its establishment under the influence of Russian literary language. Such position presupposes the need of providing a number of scientific and educational events in association with Memorial Day of Slavic Teachers and other dates, dedicated to language and book-learning. These events aid to redeeming the lost educational opportunities in bachelors' philological training, as they help to build up beneficial cultural, educational and spiritual space, which is based on the traditions of «honouring the bookish», dating back to the Slavic enlighteners. A seventeen-year experience of holding such events helps not only to generalize existing study material, but also to introduce a system of extracurricular communication among educators, students and schoolchildren, contributing to integration of educational and disciplinary processes with scientific research work.

Key words: philological education, project activities, Day of Slavic Alphabet and Culture, enlightenment, Cyril and Methodius' activities, Glagolic script, Cyrillic script.

Elena N. Bekasova, PhD in Philology, Associate Professor, Department of Russian Language and Teaching Methods of Russian Language of the Orenburg State Pedagogical University. Phone: +7-922-552-93-29; e-mail: bekasova@mail.ru 